ARTICLE

Received 12 May 2013 | Accepted 22 May 2014 | Published 30 Jun 2014 DOl: 10.1038/ncomms5193

\title{
Water clustering on nanostructured iron oxide films
}

\author{
Lindsay R. Merte ${ }^{1,2}$, Ralf Bechstein ${ }^{1, \dagger}$, Guowen Peng ${ }^{3}$, Felix Rieboldt ${ }^{1}$, Carrie A. Farberow ${ }^{3}$, Helene Zeuthen ${ }^{1}$, \\ Jan Knudsen ${ }^{1} \dagger$, Erik Lægsgaard', Stefan Wendt ${ }^{1}$, Manos Mavrikakis ${ }^{3}$ \& Flemming Besenbacher ${ }^{1}$
}

The adhesion of water to solid surfaces is characterized by the tendency to balance competing molecule-molecule and molecule-surface interactions. Hydroxyl groups form strong hydrogen bonds to water molecules and are known to substantially influence the wetting behaviour of oxide surfaces, but it is not well-understood how these hydroxyl groups and their distribution on a surface affect the molecular-scale structure at the interface. Here we report a study of water clustering on a moiré-structured iron oxide thin film with a controlled density of hydroxyl groups. While large amorphous monolayer islands form on the bare film, the hydroxylated iron oxide film acts as a hydrophilic nanotemplate, causing the formation of a regular array of ice-like hexameric nanoclusters. The formation of this ordered phase is localized at the nanometre scale; with increasing water coverage, ordered and amorphous water are found to coexist at adjacent hydroxylated and hydroxyl-free domains of the moire structure.

\footnotetext{
${ }^{1}$ Interdisciplinary Nanoscience Center (iNANO) and Department of Physics and Astronomy, Aarhus University, DK-8000 Aarhus, Denmark. ${ }^{2}$ Division of Synchrotron Radiation Research, Lund University, Box 118, S-221 00 Lund, Sweden. ${ }^{3}$ Department of Chemical and Biological Engineering, University of Wisconsin-Madison, Madison, Wisconsin 53706, USA. †Present addresses: Institute of Physical Chemistry, Johannes Gutenberg University Mainz, Duesbergweg 10-14, 55099 Mainz, Germany (R.B); MAX IV Laboratory and Division of Synchrotron Radiation Research, Lund University, Box 118, S-221 00 Lund, Sweden (J.K). Correspondence and requests for materials should be addressed to M.M. (email: manos@engr.wisc.edu) or to F.B.

(email: fbe@inano.au.dk).
} 
M otivated by applications in diverse fields such as electrochemistry, geochemistry, atmospheric chemistry, corrosion and catalysis, the structure of water adsorbed on solid surfaces has been a topic of strong and sustained interest over the past decades ${ }^{1-4}$. Due to the relative strength and particular directionality of interactions between water molecules, which are delicately balanced against molecule-surface interactions, the structures of water monolayers on various surfaces exhibit surprising diversity. This has been recently demonstrated in scanning tunnelling microscopy (STM) studies ${ }^{5-8}$, which allow direct visualization of hydrogen bonding networks. The most detailed insight into water adsorption has been achieved for single-crystal metal surfaces, where the structure of water layers is determined mainly by the dimensions of the surface unit cell and the strength of metal-oxygen bonding ${ }^{6}$.

The adsorption and clustering of water on metal oxide surfaces are very relevant for applications, as these materials are ubiquitous under ambient and aqueous conditions. Oxides add an additional level of complexity compared with metals, as water molecules can bond both to metal cations and oxide anions, and in addition, adhere strongly to $\mathrm{OH}$ groups formed by water dissociation at lattice sites or at abundant structural defects ${ }^{3,9-17}$. Although these fundamental aspects of water adsorption on oxide surfaces have been well-established, comparatively few microscopy studies have been conducted to provide detailed information about the structures formed and the influence of defects. As a result, understanding of water adsorption on oxides remains far behind that of adsorption on metals.

An additional relevant factor in the adsorption of water on the surfaces of natural or man-made materials is the fact that many such materials have nanometre-scale dimensions, and thus present an adsorption landscape for water which is inhomogeneous. Such inhomogeneity can lead to the formation of distinct nanometre-scale water structures, as observed on a boron nitride nanomesh ${ }^{18}$, or can disrupt the formation of an ordered phase, as observed on stepped Pt surfaces ${ }^{19}$. On oxide surfaces, an inhomogeneous distribution of defects or the presence of different facets can lead to a strongly varying distribution of $\mathrm{OH}$ groups, creating large variations in hydrophilicity over short length scales $^{16}$. In general it is not well-understood how nanoscale variations in surface structure impact the formation and structure of the first few wetting layers on oxide surfaces.

Monolayer $\mathrm{FeO}$ grown on $\mathrm{Pt}(111)$, first reported by Vurens et al. ${ }^{20}$, exhibits a $2.5 \mathrm{~nm}$ moiré superstructure due to the $\sim 10 \%$ lattice mismatch between the $\mathrm{FeO}$ film and the substrate ${ }^{21}$. The resulting modulation in the film's structure, best understood in terms of periodic variation in $\mathrm{Fe}-\mathrm{O}$ buckling normal to the surface, creates an inhomogeneous adsorption potential ${ }^{22}$, so that adsorbed atoms and molecules have been found to form arrays with the periodicity of the film's superstructure instead of forming larger, more random aggregates ${ }^{23,24}$. Although previous temperature-programmed desorption (TPD), infrared reflection absorption spectroscopy and ultraviolet photoelectron spectroscopy studies of water adsorbed on ultra-thin $\mathrm{FeO}(111)$ films have shown rather weak interactions between water and the surface $^{12,25,26}$, no microscopy studies have been reported to date and the potential effect of the films' moire structure on the adsorption has not been considered. Additionally, as demonstrated in previous studies ${ }^{27-29}, \mathrm{OH}$ groups can be introduced to the $\mathrm{FeO}$ surface in a well-controlled manner by exposure to atomic hydrogen, enabling us to directly and systematically study the effects of hydroxylation on $\mathrm{H}_{2} \mathrm{O}$ adsorption and clustering. As will be discussed below, the $\mathrm{OH}$ groups formed in this manner also show a distinct spatial distribution following the film's moiré structure, allowing us to examine the impact of nanometre-scale variations in defect density.
We report here a combined experimental and theoretical study of water adsorption, clustering and desorption on bare and hydroxylated monolayer $\mathrm{FeO} / \mathrm{Pt}(111)$ at low temperatures. Our results show that hydroxyl groups on the $\mathrm{FeO}$ film promote the formation of an ordered, ice-like phase, in contrast to the disordered structure formed on the bare surface. The $\mathrm{OH}$ groups are localized at one particular domain of the $\mathrm{FeO}$ film's moiré unit cell, such that the surface exhibits alternating hydrophilic and hydrophobic regions with a periodicity of $\sim 2.5 \mathrm{~nm}$. Despite the small length scale, it is found that the ordered phase only forms at the hydrophilic domains-not at adjacent hydrophobic domains.

\section{Results}

Hydroxylation of $\mathrm{FeO}$ with atomic hydrogen. An STM image of the bare $\mathrm{FeO} / \mathrm{Pt}(111)$ surface is displayed in Fig. 1a, with a structural model of the film shown in Fig. 1b. As is clear in the STM image, the $\mathrm{FeO}$ film exhibits a distinct moiré superstructure, which can be described in terms of three high-symmetry domains. These domains are distinguished by the local stacking sequence of the $\mathrm{Fe}$ and $\mathrm{O}$ layers relative to the high-symmetry points of the $\mathrm{Pt}(111)$ surface. At the FCC domain (square), Fe ions reside above $f c c$ hollow sites and $\mathrm{O}$ ions reside above $h c p$ hollow sites; at the HCP domain (triangle), Fe ions reside above
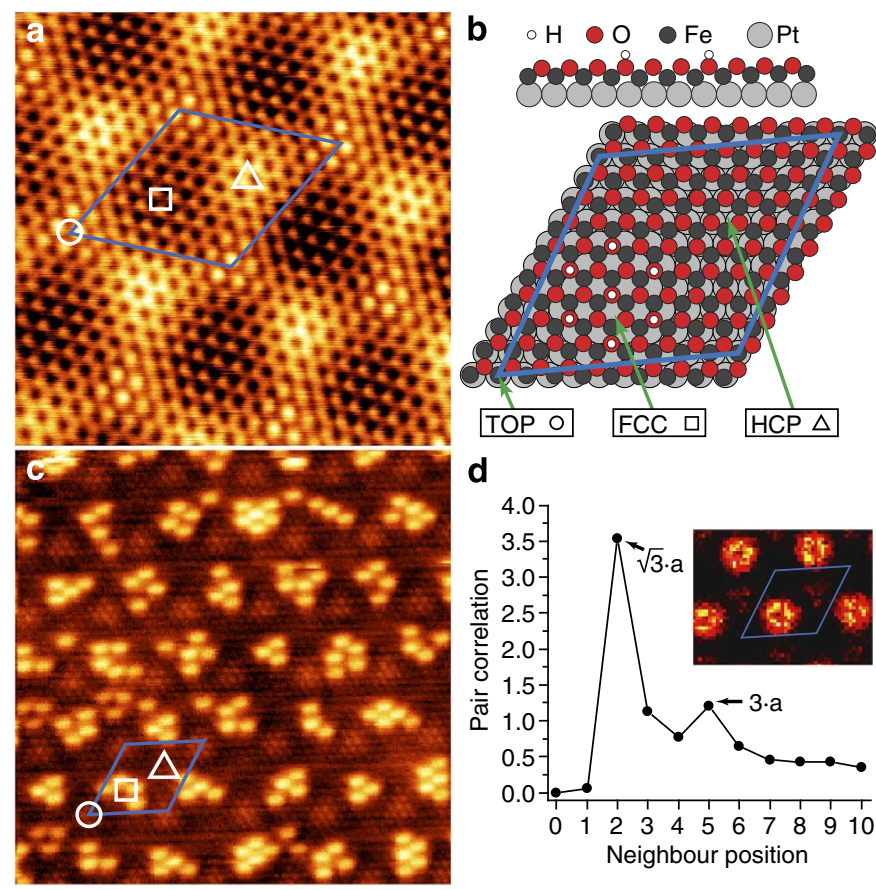

d

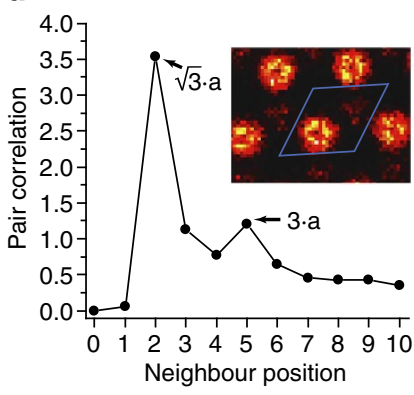

Figure 1 | Bare and hydroxylated FeO films. (a) STM image of the bare $\mathrm{FeO} / \mathrm{Pt}(111)$ film $\left(65 \times 65 \AA^{2}, 65 \mathrm{mV}, 3 \mathrm{nA}\right)$. The moiré unit cell and highsymmetry domains are indicated. Circle, square, and triangle are used to denote TOP, FCC and HCP domains, respectively. (b) Ball model of the FeO/Pt(111) film. The $\sim 25 \AA$ moiré unit cell is indicated as are the three high-symmetry domains. $\mathrm{OH}$ groups are shown (with white dots for $\mathrm{H}$ atoms) in the preferred FCC domain of the moire unit cell in their preferred $(\sqrt{3} \times \sqrt{3}) \mathrm{R} 30^{\circ}$ arrangement. (c) STM image $\left(140 \times 140 \AA^{2}, 0.7 \mathrm{~V}\right.$, $0.4 \mathrm{nA}$ ) of the hydroxylated $\mathrm{FeO}$ film with an $\mathrm{OH}$ coverage of $0.05 \mathrm{ML}$, acquired at $160 \mathrm{~K}$ after additionally dosing $\sim 0.02 \mathrm{ML}$ water (not visible). (d) Pair correlation function for $\mathrm{OH}$ groups showing peaks at the second nearest neighbour and fifth nearest neighbour positions, indicating local $(\sqrt{3} \times \sqrt{3}) \mathrm{R} 30^{\circ}$ ordering. Inset: distribution of $\mathrm{OH}$ groups within the moiré cell, showing the preference for occupation of FCC domains. 
hcp hollow sites and $\mathrm{O}$ ions reside above Pt atoms; at TOP domains (circle), $\mathrm{Fe}$ ions reside above $\mathrm{Pt}$ atoms and $\mathrm{O}$ ions reside above $f c c$ hollow sites. Unambiguous identification of the different domains in STM images has been achieved through intentional creation of defects in the $\mathrm{FeO}$ film ${ }^{30,31}$. It has been shown that, under the imaging conditions of Fig. 1a, the bright points in the TOP domains correspond to Fe ions while the bright points at the FCC domains correspond to $\mathrm{O}$ ions ${ }^{30}$.

Figure 1c shows an STM image of an $\mathrm{FeO}$ film which has been exposed to atomic hydrogen, leading to protonation of $\sim 5 \%$ of the FeO lattice oxygen ions (see Fig. 1b). Throughout this work we refer to these protonated $\mathrm{O}$ ions as hydroxyls or $\mathrm{OH}$ groups, and to the surface prepared in this way as being hydroxylated. The image in Fig. 1c was acquired at $160 \mathrm{~K}$ after additionally dosing $\sim 0.02$ monolayer (ML) water onto the surface to promote $\mathrm{H}$ atom mobility ${ }^{29}$, allowing equilibration of the structure, and to ensure that the effects of adsorbed water on the spatial distribution of $\mathrm{OH}$ groups are accounted for. This results in a more well-ordered distribution compared with what is observed directly after $\mathrm{H}$ atom exposure (see Supplementary Fig. 1). The $\mathrm{OH}$ groups appear in STM images as bright protrusions ${ }^{31}$, and due to rapid diffusion at this temperature, the coadsorbed $\mathrm{H}_{2} \mathrm{O}$ is not visible. From the distribution of $\mathrm{OH}$ groups relative to the moiré structure (Fig. 1d, inset), we find a strong preference for occupation of FCC domains, followed by partial occupation of $\mathrm{HCP}$ domains. The local arrangement of $\mathrm{OH}$ groups is also not random, as evidenced by their pair correlation function extracted from this image, plotted in Fig. 1d. Here the prominent peak at the second-nearest-neighbour position (corresponding to a separation of $\sqrt{ } 3 \cdot a$, where $a$ is the $3.1 \AA \mathrm{FeO}$ lattice parameter) and smaller peak at the fifth-nearest-neighbour position (corresponding to a separation of $3 \cdot a$ ) indicate a strong tendency towards local $(\sqrt{3} \times \sqrt{ } 3)$ R $30^{\circ}$ ordering. Such an arrangement is depicted in Fig. 1b. Density functional theory (DFT) calculations show that the $(\sqrt{3} \times \sqrt{3}) \mathrm{R} 30^{\circ}$ ordering results essentially from repulsion between neighbouring $\mathrm{OH}$ groups; the binding energy of a single $\mathrm{H}$ atom in the FCC domain is $-2.75 \mathrm{eV}$, while the differential binding energy of a second $\mathrm{H}$ atom at a nearest-neighbour site is $-2.65 \mathrm{eV}$ and at a secondnearest-neighbour site is $-2.73 \mathrm{eV}$. Thus, the second hydroxyl at the second-nearest-neighbour site is $0.08 \mathrm{eV}$ more stable than that in the nearest-neighbour configuration.

Effect of hydroxylation on water clustering. Figure 2a shows an STM image of water on bare $\mathrm{FeO}$ at $110 \mathrm{~K}$, following exposure at $\sim 130 \mathrm{~K}$. Adsorbed water forms two-dimensional islands on the terraces and elongated clusters along the step edges. The irregular shapes of the water islands on the terraces result from the moiré structure, with voids formed preferentially at one type of domain, appearing brightest in the STM image (see contrast-enhanced inset in Fig. 2a), several of which are marked with grey dots. Under the imaging conditions employed here $(+1.4 \mathrm{~V}, 0.2 \mathrm{nA})$, these bright regions in STM images of the bare FeO film correspond to TOP domains ${ }^{30}$ where Fe ions occupy sites above Pt atoms. The tendency of water to avoid wetting these domains is an indication that interactions between water molecules and $\mathrm{Fe}$ ions play no significant role in the structure; we find by DFT calculations that water monomers adsorb most strongly $(-0.21 \mathrm{eV}$ adsorption energy) at $\mathrm{Fe}$ sites of TOP domains, where a larger in-plane atomic spacing and smaller Fe-O rumpling make these cations more easily accessible compared with the FCC and HCP domains, where monomer adsorption energies of -0.11 and $-0.13 \mathrm{eV}$ were calculated. The strong preference for water to occupy FCC and HCP domains rather than TOP domains is therefore attributed to the significantly

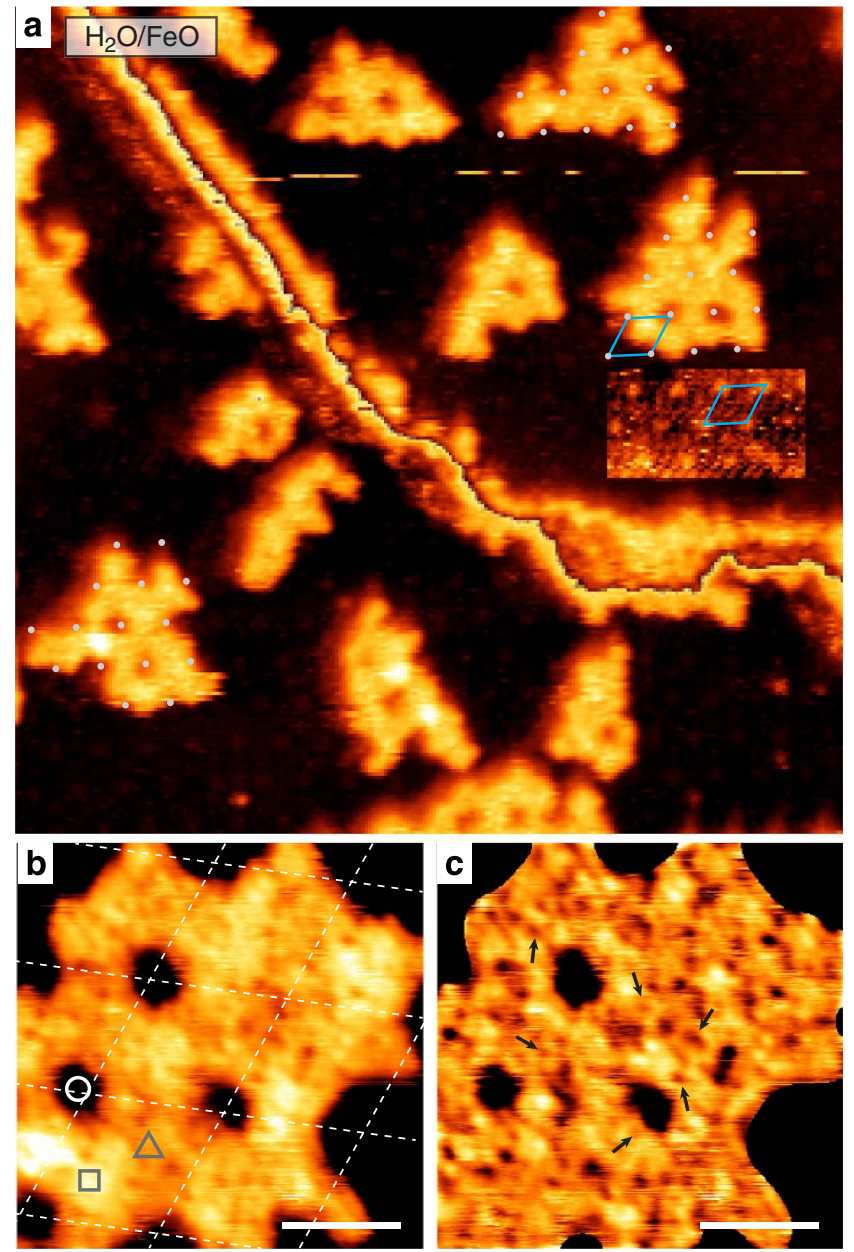

Figure 2 | Water adsorption on bare FeO. (a) STM image $\left(480 \times 480 \AA^{2}\right)$ of water adsorbed on the bare $\mathrm{FeO} / \mathrm{Pt}(111)$ film, acquired at $110 \mathrm{~K}$. The moire unit cell is indicated in blue and the positions of TOP domains in the vicinity of three $\mathrm{H}_{2} \mathrm{O}$ islands are indicated with grey dots. The rectangular area shows enhanced contrast of the bare $\mathrm{FeO}$ film, where bright spots are seen corresponding to the TOP domains. The image shows two terraces (higher terrace in the upper right) separated by a single-atomicheight step in the $\mathrm{Pt}(111)$ substrate. A cyclic colour scale is used to improve contrast. (b) High-magnification STM image of a $\mathrm{H}_{2} \mathrm{O}$ island on the bare FeO film. This image is the average of four successive STM measurements at $110 \mathrm{~K}$. The grid marks the moire unit cells, and the different domains are labelled as in Fig. 1b. Scale bar, $20 \AA$. (c) The same STM image as in $\mathbf{b}$ after subtraction of the long-range height variations. Arrows indicate some of the $4-5 \AA$ pores observed in the structure. Scale bar, $20 \AA$.

weaker electrostatic field above $\mathrm{O}$ atoms at TOP domains caused by the smaller rumpling of the $\mathrm{FeO}^{22,32,33}$.

A high-resolution STM image of one water island on the bare $\mathrm{FeO}$ film is shown in Fig. 2b. Despite some enhanced noise in such images, suggesting possible diffusion of the molecules or interactions with the STM tip, sequential images of the same island acquired over a period of $\sim 2$ min show the structure to be essentially static (see Supplementary Fig. 2). To increase the signal-to-noise ratio, four sequentially-acquired STM images were averaged to obtain the image shown in Fig. 2b. To further enhance the molecular-scale contrast, we removed the long-range variation in apparent height of the water layer by subtraction of a polynomial background (see Supplementary Fig. 3), and the result is displayed in Fig. 2c. Although individual water molecules are 
not resolved, the image clearly shows an absence of crystalline order, indicating the formation of an amorphous hydrogenbonded network. Several pores are discernible with diameters in the range of $4-5 \AA$, some of which are indicated in Fig. 2c. These pores arise from ring structures incorporating roughly $5-6 \mathrm{H}_{2} \mathrm{O}$ molecules, similar to those observed in ordered structures on metal surfaces ${ }^{4,5}$.

The apparent height of the water layer varies between the different domains of the $\mathrm{FeO}$ moire structure. Considering the very weak chemical interactions between the molecules and the surface, these differences may indicate variations in the height of the water layer above the $\mathrm{FeO}$ film. According to DFT calculations ${ }^{30}$ the heights of the $\mathrm{FeO}$ oxygen ions above the $\mathrm{Pt}$ interface layer follow the order TOP $(307 \mathrm{pm})>$ FCC $(304 \mathrm{pm})>\mathrm{HCP}(298 \mathrm{pm})$, whereas the apparent height of the water layer above the FCC domains is consistently larger than that over the HCP domains and the single occupied TOP domain by $15-30 \mathrm{pm}$. This observation is consistent with the stronger electrostatic field at the FCC domains, causing a greater tendency towards vertical orientation of the water molecules, with $\mathrm{O}-\mathrm{H}$ bonds directed towards the surface ${ }^{34}$.

The presence of surface hydroxyls on the FeO film, introduced using atomic hydrogen, changes the adsorption behaviour of water entirely, as demonstrated in Fig. 3a. Here instead of extended islands, we observe small, separated water clusters confined to the FCC domains of the moire unit cells. Thus, the strong affinity of water for surface $\mathrm{OH}$ groups enables the $\mathrm{FeO}$ film, which itself exhibits a relatively flat potential energy surface for water adsorption, to act as a nanoscale template for water clusters.

In addition to altering the size and shape of water clusters formed on $\mathrm{FeO}$, the presence of $\mathrm{OH}$ groups has a striking effect on the molecular-scale ordering of the water within the clusters. Figure $3 \mathrm{~b}$ shows high-magnification STM images of $\mathrm{H}_{2} \mathrm{O}$ clusters of various sizes observed on a hydroxylated $\mathrm{FeO}$ film. The clusters exhibit a distinct hexagonal ring motif with apparent $(\sqrt{ } 3 \times \sqrt{ } 3) \mathrm{R} 30^{\circ}$ symmetry, similar to ring structures that have been observed on several metal surfaces ${ }^{2}$. Assuming that the preferential $(\sqrt{ } 3 \times \sqrt{ } 3) \mathrm{R} 30^{\circ}$ ordering of $\mathrm{OH}$ groups observed on $\mathrm{FeO}$ (Fig. 1c,d) is retained upon exposure to water, half of the $\mathrm{H}_{2} \mathrm{O}$ molecules in the hexagonal structure should lie flat, accepting hydrogen bonds from the surface $\mathrm{OH}$ while the other half should be oriented vertically, donating hydrogen bonds to surface $\mathrm{O}$ ions. A schematic model of the proposed structure is depicted in Fig. 3c.

DFT calculations of water clusters on FeO. To gain further insight into the water structures observed on the hydroxylated surface, we carried out DFT + U calculations using, for simplicity, a single cyclic water hexamer ${ }^{35,36}$ adsorbed at the FCC domain of the FeO film populated with $\mathrm{OH}$ groups arranged in a $(\sqrt{3} \times \sqrt{ } 3)$ $\mathrm{R} 30^{\circ}$ pattern (see Fig. 1b). The cyclic hexamer is the basic structural motif of ice $\mathrm{I}_{\mathrm{h}}$. The most stable isomer in the gas phase has $S_{6}$ symmetry and each $\mathrm{H}_{2} \mathrm{O}$ molecule simultaneously acts as a $\mathrm{H}$-bond donor and acceptor (Supplementary Fig. 4). The relaxed, lowest-energy structure of an $S_{6}$-like water hexamer adsorbed onto hydroxylated $\mathrm{FeO}$, whose symmetry is reduced upon adsorption to that of point group $C_{3}$, is depicted in Fig. 4a,b. Three of the six $\mathrm{H}_{2} \mathrm{O}$ molecules are oriented parallel to the surface, accepting hydrogen bonds from the surface $\mathrm{OH}$ (green dashed lines in Fig. 4a), and the remaining three $\mathrm{H}_{2} \mathrm{O}$ molecules are oriented perpendicular to the surface, with one $\mathrm{O}-\mathrm{H}$ bond oriented downwards towards a surface $\mathrm{O}$ atom (white dashed lines in Fig. 4a).

The hydrogen bonds inside the cyclic ring have two different general lengths, which alternate around the ring. This can be

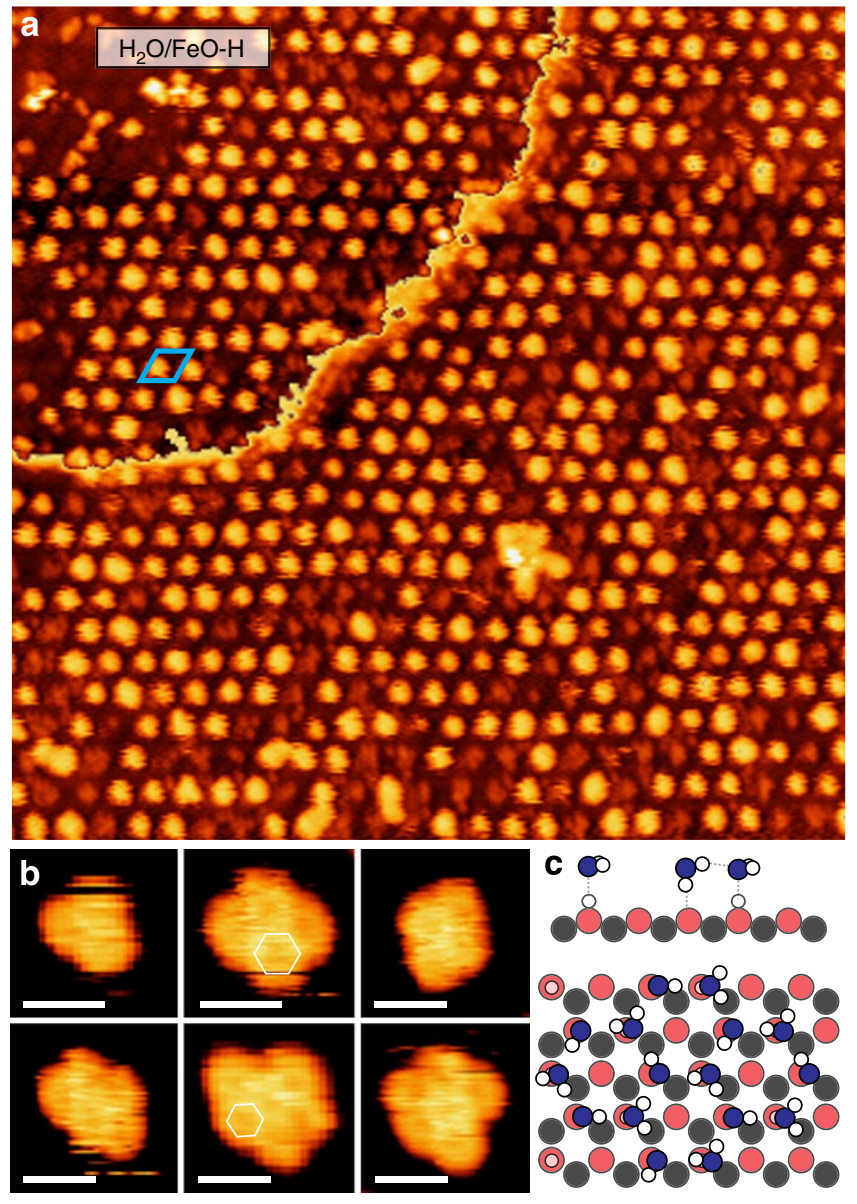

Figure 3 | Water adsorption on hydroxylated FeO. (a) STM image $\left(600 \times 600 \AA^{2}\right)$ of water adsorbed on a hydroxylated FeO film with an $\mathrm{OH}$ coverage of $0.05 \mathrm{ML}$, acquired at $110 \mathrm{~K}$. The moiré unit cell is indicated in blue. The image shows two terraces (higher terrace in the upper left) separated by a single-atomic-height step in the Pt(111) substrate. A cyclic colour scale is used to improve contrast. (b) High-magnification images of $\mathrm{H}_{2} \mathrm{O}$ clusters on hydroxylated $\mathrm{FeO}$ showing a hexagonal ring structure. Scale bars, $10 \AA$. (c) Schematic model of the hexagonal ring structure on hydroxylated FeO inferred from STM measurements; upper section gives a cross-section view; bottom an atop view.

understood by focusing on one parallel-oriented water molecule: The accepted H-bond is longer (1.85-1.87 $\mathrm{A})$, whereas the donated H-bond is shorter (1.53-1.55 $\AA$ ). Inside the cyclic ring the average length of $\mathrm{H}$-bonds is $1.70 \AA$, slightly longer (by $0.05 \AA$ ) than that of a cyclic water hexamer in the gas phase (Supplementary Fig. 4), due to the influence of hydrogen bonds with the surface. The $\mathrm{H}$-bonds between the parallel $\mathrm{H}_{2} \mathrm{O}$ and surface $\mathrm{OH}$ are in the range of 1.57-1.61 $\AA$, while the $\mathrm{H}$-bonds between the perpendicular $\mathrm{H}_{2} \mathrm{O}$ and surface $\mathrm{O}$ are longer (1.72$1.81 \AA$ ). The parallel $\mathrm{H}_{2} \mathrm{O}$ molecules are slightly tilted relative to the surface, with an average vertical displacement of $0.35 \AA$ between the two $\mathrm{H}$ in the parallel $\mathrm{H}_{2} \mathrm{O}$. This displacement is smaller than the value for the $S_{6}$ hexamer in the gas phase $(0.78 \AA$, projected along the $S_{6}$ axis).

The average adsorption energy of $\mathrm{H}_{2} \mathrm{O}$ in the $C_{3}$ hexamer (Fig. 4a,b), relative to isolated, gas-phase $\mathrm{H}_{2} \mathrm{O}$ molecules, is calculated to be $-0.68 \mathrm{eV}$ per $\mathrm{H}_{2} \mathrm{O}$. For reference, the adsorption energy of an isolated $\mathrm{H}_{2} \mathrm{O}$ molecule hydrogen bonded to a surface $\mathrm{OH}$ is $-0.62 \mathrm{eV}$ and that of an isolated molecule on the bare $\mathrm{FeO}$ surface ranges from -0.1 to $-0.2 \mathrm{eV}$, depending on the moiré 

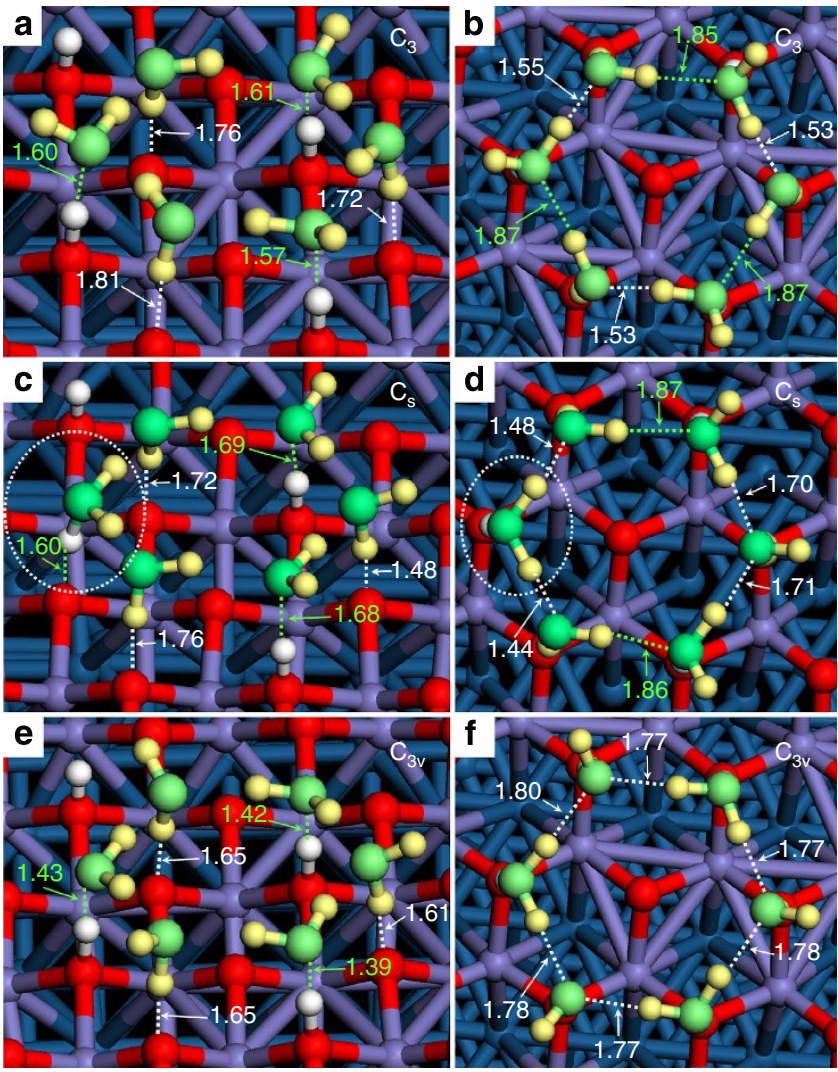

Figure 4 | Atomic structures of water clusters on hydroxylated FeO. Tilted side $(\mathbf{a}, \mathbf{c}, \mathbf{e})$ and top $(\mathbf{b}, \mathbf{d}, \mathbf{f})$ views of three cyclic water hexamers, differing in the orientations of the molecules, adsorbed on the hydroxylated $\mathrm{FeO}$ film as determined by DFT $+U$ calculations. All numerical values for bond lengths are in $\AA$. Green (white) dashed lines in $\mathbf{a}, \mathbf{c}, \mathbf{e}$ indicate hydrogen bonds between the hexamer and the surface where the water acts as a hydrogen bond acceptor (donor). Green (white) dashed lines in $\mathbf{b}, \mathbf{d}, \mathbf{f}$ indicate hydrogen bonds where the parallel water is accepting (donating) a hydrogen bond. Note the transfer of one $\mathrm{H}^{+}$ion from the surface to one water molecule, forming a hydronium $\left(\mathrm{H}_{3} \mathrm{O}^{+}\right)$ion, in the $\mathrm{C}_{s}$ structure, highlighted by dashed white ovals in $\mathbf{c}, \mathbf{d}$. Blue, purple, red and white spheres indicate $\mathrm{Pt}, \mathrm{Fe}, \mathrm{O}$ and $\mathrm{H}$ atoms, respectively. $\mathrm{H}$ and $\mathrm{O}$ atoms in $\mathrm{H}_{2} \mathrm{O}$ are highlighted by yellow and green spheres, respectively.

domain. $\mathrm{H}_{2} \mathrm{O}$ adsorbed as a $C_{3}$ hexamer on the bare FeO surface (Supplementary Fig. 5) has a mean adsorption energy of $-0.42 \mathrm{eV}$ per $\mathrm{H}_{2} \mathrm{O}$ molecule (referenced to isolated gas-phase $\mathrm{H}_{2} \mathrm{O}$ ), nearly all of which is due to intermolecular hydrogen bonding; for a similar $S_{6}$ cyclic hexamer in the gas phase (Supplementary Fig. 4) we calculate a formation energy of $-0.39 \mathrm{eV}$ per $\mathrm{H}_{2} \mathrm{O}$.

In bulk ice $\mathrm{I}_{\mathrm{h}}$, where all $\mathrm{H}_{2} \mathrm{O}$ molecules are found in a tetrahedral bonding arrangement, each donating and accepting two hydrogen bonds to its neighbours, the positions of the protons (that is, the orientations of the water molecules) do not exhibit crystalline order but are instead random, within the constraint that the $\mathrm{H}$-bonds remain saturated, and a transition to an ordered structure only occurs at very low temperatures ${ }^{37}$. Breaking of the bulk symmetry, as occurs at surfaces and in nanostructures, has the potential to induce proton ordering by eliminating the near-degeneracy of structures with water molecules in different orientations ${ }^{38,39}$.

To investigate the extent of proton ordering in $\mathrm{H}_{2} \mathrm{O}$ nanoclusters on $\mathrm{FeO}$, we performed additional calculations using a different cyclic hexamer where one of the $\mathrm{H}_{2} \mathrm{O}$ molecules acts as a double $\mathrm{H}$-bond donor, and a second acts as a double $\mathrm{H}$-bond acceptor (Fig. 4c,d). This cyclic $\mathrm{H}_{2} \mathrm{O}$ hexamer has $C_{s}$ symmetry and is $0.89 \mathrm{eV}$ less stable in the gas phase than the $S_{6}$ hexamer discussed above. Remarkably, when adsorbed on hydroxylated $\mathrm{FeO}$, the $C_{s}$ hexamer is nearly isoenergetic with the adsorbed $C_{3}$ hexamer; the calculated average adsorption energy is $-0.66 \mathrm{eV}$ per $\mathrm{H}_{2} \mathrm{O}$. A third hexamer, characterized by $C_{3 v}$ symmetry, with three double $\mathrm{H}$-bond donors and three double $\mathrm{H}$-bond acceptors (Fig. 4e,f), was likewise similar in energy to the adsorbed $C_{3}$ and $C_{s}$ hexamers; although unstable in the gas-phase calculation (it converged to the $S_{6}$ structure), on hydroxylated $\mathrm{FeO}$ the adsorption energy was calculated as $-0.67 \mathrm{eV}$ per $\mathrm{H}_{2} \mathrm{O}$. Although the differences in energy between these configurations are too small to predict which will be dominant in experimentally-observable $\mathrm{H}_{2} \mathrm{O}$ clusters ${ }^{40,41}$, it is clear that the hydroxylated $\mathrm{FeO}$ surface significantly stabilizes bonding configurations that otherwise are unfavourable. This very likely leads to a significantly greater degree of proton disorder than would be expected based on gas-phase results.

In the gas phase, the striking differences in stability of the three different cyclic hexamers result from the cooperative nature of hydrogen bonds in water ${ }^{42,43}$. Formation of a hydrogen bond between water molecules involves a polarization of each molecule's electronic charge density towards the region between the two molecules where the hydrogen bond is formed. This polarization depletes electronic charge from the covalent $\mathrm{O}-\mathrm{H}$ bonds of the acceptor molecule, increasing its tendency to act as a donor to another $\mathrm{H}_{2} \mathrm{O}$ molecule, which in turn experiences a similar polarization, and so on. The result is, depending on the configuration, an enhancement or diminishment in mean hydrogen bond strength compared with what would be expected based on pairwise interactions, that is, that observed in an $\mathrm{H}_{2} \mathrm{O}$ dimer. In the $S_{6}$ water hexamer, the position of each molecule as a simultaneous $\mathrm{H}$-bond donor and acceptor takes full advantage of these effects and a corresponding increase in stability is observed. In the $C_{s}$ and $C_{3 v}$ hexamers, however, molecules are found which either donate two hydrogen bonds without accepting any, or which accept two hydrogen bonds without donating any. This unfavourable configuration leads to a reduction in hydrogen bond strength, significantly destabilizing the structures.

However, by interaction with the hydroxylated $\mathrm{FeO}$ surface such effects are almost fully compensated. In the $C_{3 v}$ structure (Fig. 4e,f), the three double-donor $\mathrm{H}_{2} \mathrm{O}$ molecules accept strong hydrogen bonds from surface $\mathrm{OH}$ groups, with calculated $\mathrm{O}-\mathrm{H}$ distances of $1.39-1.43 \AA$, while the three double-acceptor $\mathrm{H}_{2} \mathrm{O}$ molecules donate relatively strong bonds to the substrate $\mathrm{O}$ ions, with calculated $\mathrm{O}-\mathrm{H}$ distances of 1.61-1.65 $\AA$. The effects are even more pronounced for the $C_{s}$ isomer, where polarization of the double-donor $\mathrm{H}_{2} \mathrm{O}$ molecule is sufficient to draw the $\mathrm{OH}$ proton away from the surface, spontaneously forming an $\mathrm{H}_{3} \mathrm{O}^{+}$ ion (indicated by the dashed oval in Fig. 4c,d). The doubleacceptor $\mathrm{H}_{2} \mathrm{O}$ at the opposite side of the molecule likewise interacts strongly with the surface, with a calculated $\mathrm{O}-\mathrm{H}$ distance of 1.48 A.

Cooperative effects are also apparent in the adhesion of the $C_{3}$ hexamer (Fig. 4a,b). The weak interaction between the hexamer and the bare $\mathrm{FeO}$ surface is reflected in the $\mathrm{H}$-bond lengths of the molecules with $\mathrm{OH}$ bonds directed towards the surface, which are calculated to be 2.06-2.07 $\AA$ (see Supplementary Fig. 5). The strong hydrogen bonds formed at surface $\mathrm{OH}$ groups on hydroxylated $\mathrm{FeO}$ impart substantial donor character to the associated flat-lying $\mathrm{H}_{2} \mathrm{O}$ molecules, which then form strong donor bonds to the neighbouring vertical $\mathrm{H}_{2} \mathrm{O}$ molecules, as reflected by the alternating bond lengths around the ring mentioned above. As a secondary effect, the acceptance of this 
strong $\mathrm{H}$-bond by the vertically-oriented $\mathrm{H}_{2} \mathrm{O}$ molecules leads to a significant contraction of the hydrogen bond lengths between these molecules and the surface O ions, to 1.72-1.81 A. Even for the FeO film, which should be considered a rather acidic oxide (on the basis of the relative strengths of donor and acceptor $\mathrm{H}$-bonds with water ${ }^{44}$ ), $\mathrm{O}$ ions adjacent to $\mathrm{OH}$ groups act as $\mathrm{H}$-bond acceptors as a result of cooperative hydrogen bonding. These interactions effectively separate the hexamer into three associated dimers, each held together by an especially strong hydrogen bond (1.53-1.55 $)$, qualitatively similar to what has been observed for water on $\mathrm{TiO}_{2}(110)^{17}$ and predicted for $\mathrm{MgO}(100)^{45}$ and $\mathrm{O} / \mathrm{Ru}(0001)^{46}$.

The substantial donor character imparted to the 'parallel' $\mathrm{H}_{2} \mathrm{O}$ molecules by $\mathrm{H}$-bonding to $\mathrm{OH}$ groups on hydroxylated $\mathrm{FeO}$ will create an effective repulsive interaction between these complexes, providing an additional driving force for the formation of a structure with $(\sqrt{3} \times \sqrt{3}) \mathrm{R} 30^{\circ}$ ordering of the underlying $\mathrm{H}$ atoms, independent of the intrinsic distribution of $\mathrm{H}$ atoms on the surface described above. A similar effect has been observed in mixed $\mathrm{OH} / \mathrm{H}_{2} \mathrm{O}$ monolayers on $\mathrm{Pt}(111)(\mathrm{OH}$ in this case referring to a distinct molecule coadsorbed with water), where very stable, ordered hexagonal structures form at a 1:1 $\left(\mathrm{OH}: \mathrm{H}_{2} \mathrm{O}\right)$ ratio as a result of alternating $\mathrm{H}$-bond donor $\left(\mathrm{H}_{2} \mathrm{O}\right)$ and acceptor $(\mathrm{OH})$ molecules ${ }^{47,48}$. Such a tendency towards donor/acceptor ordering is expected to occur as a general feature of water adsorption on hydroxylated oxide surfaces, to the extent this is compatible with the geometric features of the specific surface.

Desorption kinetics. To investigate the effect of hydroxylation on the desorption behaviour of water, we conducted TPD measurements on the bare $\mathrm{FeO}$ film and on films with various $\mathrm{OH}$ coverages (Fig. 5). For each surface, prepared initially by exposure of the $\mathrm{FeO}$ film to atomic hydrogen, $\mathrm{H}_{2} \mathrm{O}$ was dosed at $130 \mathrm{~K}$ and TPD traces were measured up to $250 \mathrm{~K}$, after which the sample was re-cooled to $130 \mathrm{~K}$ and the next measurement was conducted. Reaction of $\mathrm{OH}$ groups to form $\mathrm{H}_{2} \mathrm{O}$, leading to irreversible reduction of the surface, occurs only above $\sim 400 \mathrm{~K}^{28}$. Similar to previous observations for a two-layer thick $\mathrm{FeO}(111)$ film $^{25}$, the TPD traces from the bare film show a single peak (denoted $\alpha$ ) for sub-monolayer coverages at $164-168 \mathrm{~K}$ and an additional peak at $\sim 158 \mathrm{~K}$ (denoted $\gamma$ ) due to adsorption on top of the first wetting layer. On the hydroxylated $\mathrm{FeO}$ surface a new feature appears in the TPD spectra at higher temperatures, $167-186 \mathrm{~K}$ (denoted $\beta$ ). With increasing $\mathrm{OH}$ coverage the $\beta$ feature becomes more prominent and shifts to higher temperatures. As can be seen by comparing the traces plotted in red in Fig. 5a-e, growth of the $\beta$ feature occurs at the expense of the $\alpha$ feature.

Interpretation of the measured TPD traces is assisted by STM measurements of different quantities of water adsorbed on $\mathrm{FeO}$ surfaces with varying $\mathrm{OH}$ coverages. The STM images in Fig. 6 illustrate the effects of the relative $\mathrm{H}_{2} \mathrm{O}$ and $\mathrm{OH}$ coverages on the size and molecular structure of adsorbed water clusters at $110 \mathrm{~K}$. Figure 6a,b shows surfaces where small and large quantities of water were dosed onto surfaces with high and low coverages of $\mathrm{OH}$ groups, respectively. On the surface (Fig. 6a) with an excess of $\mathrm{OH}$ groups, whose coverage is sufficient to populate HCP domains as well as FCC domains, we observed that the islands exhibit a clear hexagonal ring structure at both the FCC and HCP domains. In contrast, on the $\mathrm{FeO}$ surface with a low coverage of $\mathrm{OH}$ groups and an excess of water (Fig. 6b), the hexagonal ring structure is only observed at FCC domains; at the HCP domains, which are unoccupied by $\mathrm{OH}$ groups, a disordered structure is observed similar to that found on the bare FeO film.

Accordingly, under the conditions of the STM experiments, adsorbed water occurs in two distinct phases: an ordered phase associated with $\mathrm{OH}$ groups, and an amorphous phase associated with the bare FeO surface. Although it cannot be ruled out that a single mixed phase is formed at temperatures higher than $110 \mathrm{~K}$, we tentatively assign the $\alpha$ and $\beta$ TPD features to desorption of a

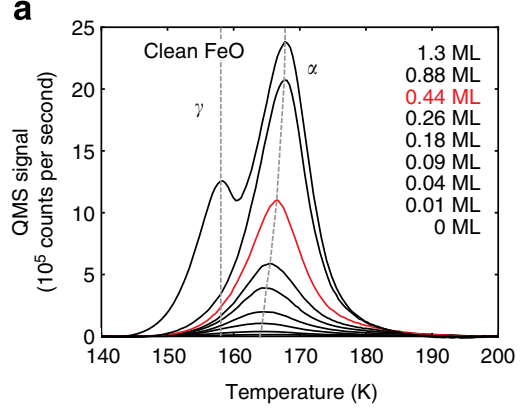

d

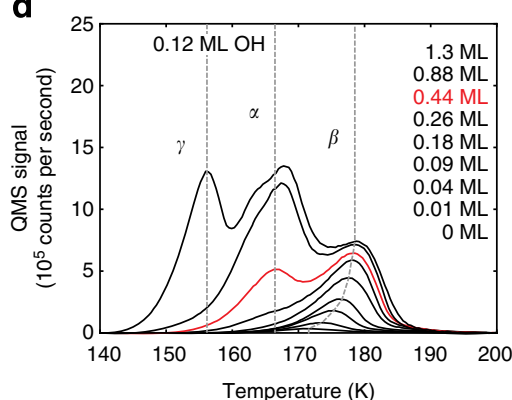

b

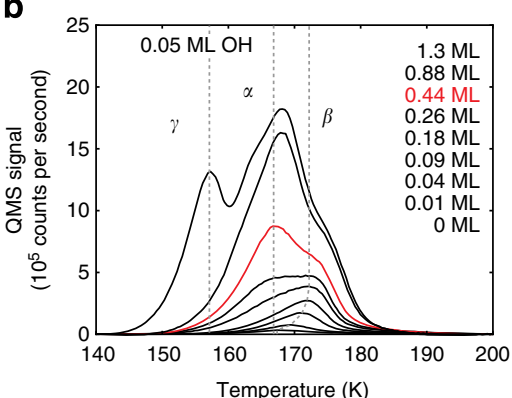

e

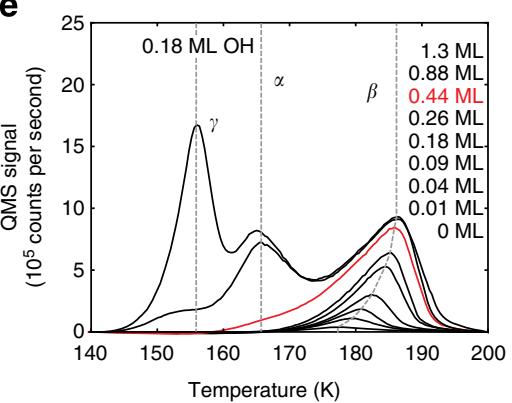

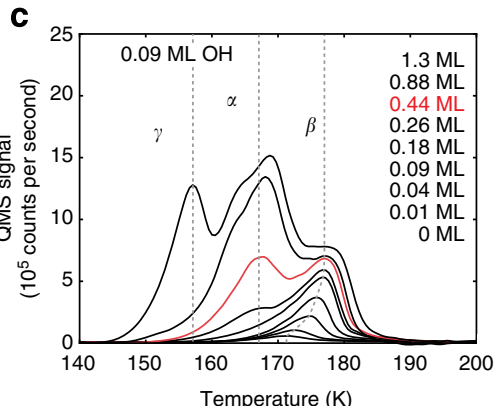

f

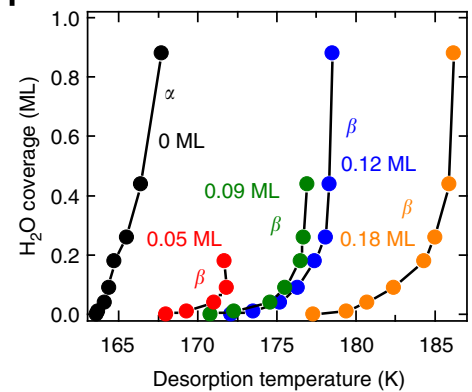

Figure $\mathbf{5}$ | Effect of hydroxylation on $\mathbf{H}_{\mathbf{2}} \mathbf{O}$ desorption kinetics. TPD measurements ( $2 \mathrm{~K} \mathrm{~s}^{-1}$ linear ramp) of $\mathrm{H}_{2} \mathrm{O}$ from (a) bare FeO/Pt(111), and hydroxylated $\mathrm{FeO}$ films with $\mathrm{OH}$ coverages of (b) $0.05 \mathrm{ML}$, (c) $0.09 \mathrm{ML}$, (d) $0.12 \mathrm{ML}$, (e) $0.18 \mathrm{ML}$. Dashed lines indicate primary desorption features (see text); traces obtained with an initial $\mathrm{H}_{2} \mathrm{O}$ coverage of $0.44 \mathrm{ML}$ are plotted in red for easy comparison. (f) Plot of the peak temperature of the highest-temperature desorption feature ( $\alpha$ for bare $\mathrm{FeO}, \beta$ for hydroxylated $\mathrm{FeO}$ ) for various $\mathrm{OH}$ coverages and $\mathrm{H}_{2} \mathrm{O}$ exposures. 


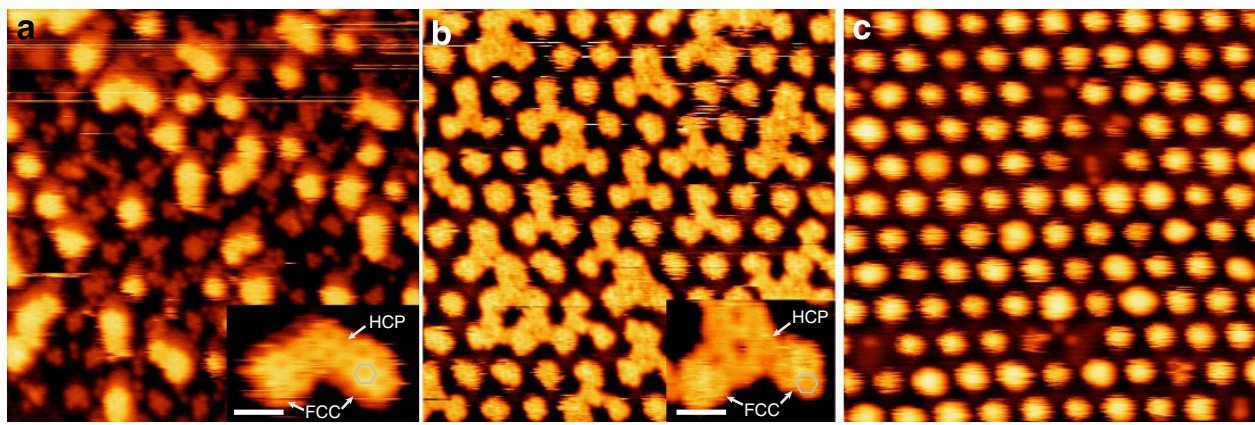

Figure 6 | Effects of $\mathbf{O H}$ and $\mathbf{H}_{\mathbf{2}} \mathbf{O}$ coverages. STM images $\left(250 \times 250 \AA^{2}\right)$ of $\mathrm{H}_{2} \mathrm{O}$ adsorbed on hydroxylated FeO with various $\mathrm{OH}$ coverages and $\mathrm{H}_{2} \mathrm{O}$ exposures. (a) $0.1 \mathrm{ML} \mathrm{H} \mathrm{O}_{2}, 0.12 \mathrm{ML} \mathrm{OH}$, (b) $0.25 \mathrm{ML} \mathrm{H} \mathrm{O}_{2} 0.05 \mathrm{MLOH}$, (c) $0.1 \mathrm{ML} \mathrm{H}_{2} \mathrm{O}, 0.05 \mathrm{ML} \mathrm{OH}$. Insets in a and b are high-resolution images of $\mathrm{H}_{2} \mathrm{O}$ clusters on the respective surfaces, showing the different structures at HCP domains with and without $\mathrm{OH}$ groups. Scale bars, $10 \AA$.

water from bare and hydroxylated regions on the $\mathrm{FeO}$ film, respectively. Note also that the $\alpha$ feature only appears in the TPD spectra when a water coverage approximately twice the $\mathrm{OH}$ coverage is exceeded, indicating that the $\beta$ feature corresponds to a phase incorporating a maximum $\mathrm{H}_{2} \mathrm{O}: \mathrm{OH}$ ratio of 2:1, as is the case for the hexagonal ring structure discussed above. Alternatively, assignment of the $\alpha$ feature to a mixed phase, in which the $\mathrm{OH}$ groups are dispersed uniformly remains a possibility. However, this possibility appears less likely, since a shift in the $\alpha$ peak as a function of the $\mathrm{OH}: \mathrm{H}_{2} \mathrm{O}$ ratio would be expected, which was barely observed. Note, however, that at the highest $\mathrm{H}_{2} \mathrm{O}$ coverages in the presence of $\mathrm{OH}$ groups, the $\alpha$ state includes two components, indicating that the $\mathrm{OH}$ groups do have some effect on the desorption kinetics, though the cause of this is not clear at present.

As noted above, the $\beta$ TPD feature, associated with water adsorption at $\mathrm{OH}$ groups, shifts to higher temperatures both with increasing $\mathrm{H}_{2} \mathrm{O}$ coverage and increasing $\mathrm{OH}$ coverage. The peak positions in the different experiments are plotted together in Fig. 5f, along with the positions of the $\alpha$ peak of the bare film for comparison. Variation in the $\beta$ desorption temperature with $\mathrm{OH}$ coverage may reflect differences in $\mathrm{H}_{2} \mathrm{O}$ cluster size due to isolation of $\mathrm{OH}$ groups in separate moiré unit cells, since the number of $\mathrm{OH}$ groups per cell determines the maximum number of water molecules that can be stabilized in each. This is supported by comparison of the STM images shown in Fig. 6a,c, obtained on surfaces with the same quantity $(0.1 \mathrm{ML})$ of water adsorbed onto $\mathrm{FeO}$ films with $\mathrm{OH}$ coverages of 0.12 and $0.05 \mathrm{ML}$, respectively. On the surface with the lower OH coverage (Fig. 6c), a large number of smaller clusters is observed, whereas on the surface with high $\mathrm{OH}$ coverage (Fig. 6a) a smaller number of larger clusters is seen. The corresponding difference in desorption temperature for these two systems is $\sim 4 \mathrm{~K}$ (Fig. $5 \mathrm{f}$ ). It is not clear from the present results whether these subtle effects, apparently due to cluster size, result from increasing thermodynamic stability with increasing size or from more complex kinetic factors.

Finally, a feature of the TPD data worth noting is the invariance of the second-layer $\gamma$ desorption temperature irrespective of the surface $\mathrm{OH}$ coverage (Fig. 5a-e). This result shows that the enhanced hydrophilicity conferred to the surface by the $\mathrm{OH}$ groups is lost after formation of the first $\mathrm{H}_{2} \mathrm{O}$ monolayer. This is similar to hydrophobic water layers studied previously on hydrophobic $\mathrm{Pt}(111)^{49}$ and graphite ${ }^{50}$ surfaces as well as on a hydrophilic kaolinite surface ${ }^{51}$. In all these cases, the preferential downward orientation of $\mathrm{O}-\mathrm{H}$ bonds in the outermost water layers left surfaces devoid of 'dangling H-bonds' which could bind strongly to the next layer of water. Our TPD results thus provide further support for the 'H-down' model of the hexagonal water structure on the hydroxylated $\mathrm{FeO}$ film, and indicate that, in spite of the very weak interactions with the surface, the structure formed on the bare $\mathrm{FeO}$ surface likewise contains few or no $\mathrm{H}_{2} \mathrm{O}$ molecules with $\mathrm{O}-\mathrm{H}$ bonds directed away from the surface. The broader implications of this result are not trivial; under ambient temperature conditions, thermal flipping of $\mathrm{O}-\mathrm{H}$ bonds away from the surface can be sufficient to create hydrophilic interactions on a surface which is hydrophobic at low temperatures, as exemplified by recent MD simulations of water interacting with kaolinite ${ }^{52,53}$.

\section{Discussion}

Our STM, DFT and TPD studies addressing water clustering on bare and hydroxylated $\mathrm{FeO}$ surfaces reveal that highly localized hydrophilic domains are formed upon hydroxylation of a moiréstructured $\mathrm{FeO}$ monolayer on $\mathrm{Pt}(111)$, such that adsorbed water forms nanometre-sized clusters rather than extended twodimensional islands. The water clusters exhibit a hexameric ring structure stabilized by hydrogen bonding with surface $\mathrm{OH}$ groups, in contrast to the larger islands on the bare surface which exhibit an amorphous structure.

The STM and DFT results suggest that within the hexagonal structure, half of the water molecules accept H-bonds from surface $\mathrm{OH}$ groups while the other half donate $\mathrm{H}$-bonds to surface $\mathrm{O}$ ions, resulting in an $\mathrm{H}_{2} \mathrm{O}: \mathrm{OH}$ ratio of 2:1. This $2: 1$ ratio is supported by TPD measurements, which show a single desorption feature for $\mathrm{H}_{2} \mathrm{O}$ coverages up to approximately twice the initial $\mathrm{OH}$ coverage. Remarkably, when this ratio is exceeded, excess water adsorbed on the surface is neither incorporated into the hexagonal structure, forming a phase with a diluted $\mathrm{OH}$ concentration, nor is it induced to form an ordered structure by proximity with the hexagonal phase. Rather, by STM, we observe a coexistence of ordered and disordered water structures on a scale of $1 \mathrm{~nm}$. This result highlights the very localized influence of $\mathrm{OH}$ groups on the structure of the adsorbed water monolayer, in contrast to what has been observed on metal surfaces, where only small concentrations of defects are sufficient to induce large-scale formation of ordered structures locked into simple registry with the substrate $e^{4}$. Detailed investigation, by DFT, of orientational ordering of water molecules in hexagonal $\mathrm{H}_{2} \mathrm{O}$ nanoclusters shows that cooperative hydrogen bonding effects play a substantial role in determining the details of the structures and the interactions between water molecules and the surface. Stronger molecule-surface interactions are found to compensate for weaker intermolecular interactions in certain structures-in one case through spontaneous formation of an $\mathrm{H}_{3} \mathrm{O}^{+}$ion-so that otherwise unfavourable configurations at the cluster edges 
are energetically comparable to the more balanced $\mathrm{H}$-bond donor-acceptor configuration which is by far most stable in the gas phase.

The discovered templating effect of the hydroxylated $\mathrm{FeO}$ film allows control of the dispersion of adsorbates, making it an intriguing surface for the study of small clusters of water and other hydrophilic species. It would be interesting to investigate the orientational ordering and proton transfer dynamics of $\mathrm{H}_{2} \mathrm{O}$ in few-molecule clusters at lower temperatures, where such structures can be fully or partially frozen. One can further envision using the hydroxylated $\mathrm{FeO}$ film to control the bottomup synthesis of nanostructures based on hydrophilic components or precursors; though the templating effects of the bare $\mathrm{FeO}$ film itself are rather weak, being observed most clearly only at very low temperatures ${ }^{23,24}$, hydrogen bonding with surface $\mathrm{OH}$ groups should significantly enhance ordering, enabling directed selfassembly at higher temperatures.

\section{Methods}

STM and TPD Measurements. Monolayer FeO films were grown ${ }^{20,54}$ by evaporation of Fe onto clean, sputtered and annealed $\mathrm{Pt}(111)$ surfaces followed by heating in $1 \times 10^{-6} \mathrm{mbar}_{2}$ at $1,000 \mathrm{~K}$. STM measurements were performed using a home-built variable-temperature Aarhus $\mathrm{STM}^{55}$, mounted in an ultra-high vacuum (UHV) chamber with a base pressure of $\sim 1 \times 10^{-10}$ mbar. For STM experiments, water exposures were performed by removing the cooled sample $(T=110 \mathrm{~K})$ from the STM block using the in-vacuum transfer arm so that the sample faced the water inlet. The tip of the transfer arm was pre-cooled by pressing it against the cold STM block for several minutes, and the dosing procedure was performed as quickly as possible $(<1 \mathrm{~min})$ to keep the sample temperature as low as possible $(<135 \mathrm{~K})$. Deionized water, degassed by several freeze-pump-thaw cycles, was dosed onto the surface using $1 \mathrm{~ms}$ pulses from a binary piezoelectric valve. Calibration of water coverages was performed by deposition onto clean $\mathrm{Pt}(111)$, where water forms an overlayer with known density ${ }^{7}$ of $1.1 \times 10^{15} \mathrm{~cm}^{-2}$. The surface coverage of $1 \mathrm{ML}$ is defined here as the density of $\mathrm{O}$ atoms in the FeO film, $1.2 \times 10^{15} \mathrm{~cm}^{-2}$. It was determined that a single pulse from the piezoelectric doser produced a water coverage of $\sim 0.02 \mathrm{ML}$ on the surface. Unless otherwise noted, STM images of water structures were acquired at $+1.0-1.5 \mathrm{~V}$ sample bias and tunnelling currents of $0.1-0.2 \mathrm{nA}$. STM image processing was conducted using the Gwyddion software package ${ }^{56}$

TPD experiments were carried out using a commercial UHV surface analysis system (SPECS), equipped with a Hiden quadrupole mass spectrometer (QMS) fitted with a glass shroud with a 4-mm entrance aperture as well as an X-ray source and electron energy analyzer for X-ray photoelectron spectroscopy, a SPECS variable-temperature STM-150 (Aarhus), and similar equipment for sample preparation as on the home-built STM system. For these experiments, a hat-shaped $\mathrm{Pt}(111)$ crystal $7 \mathrm{~mm}$ in diameter was used, with a type $\mathrm{K}$ thermocouple spotwelded to the side of the crystal. Liquid nitrogen cooling allowed the sample to be cooled to $\sim 110 \mathrm{~K}$, and a filament placed behind the sample provided radiative and electron-beam heating up to $\sim 1,200 \mathrm{~K}$. Water was dosed at $130 \mathrm{~K}$ by backfilling the chamber with a leak valve and a Eurotherm temperature controller was used to provide the linear heating ramp for the TPD experiments, which was set at $2 \mathrm{Ks}^{-1}$ for all measurements.

For experiments in both chambers, $\mathrm{H}$ atoms were produced from $\mathrm{H}_{2}$ using thermal gas crackers and their coverage was determined by STM. Exposures were performed with the sample at room temperature, with the exception of the highest $\mathrm{OH}$ coverage $(0.18 \mathrm{ML})$, where the sample was held at $130 \mathrm{~K}$ to prevent reduction of the $\mathrm{FeO}$ film ${ }^{28}$.

DFT Calculations. All calculations were performed using the Vienna Ab initio Simulation Package ${ }^{57,58}$ based on spin-polarized DFT. We used the DFT $+U$ approach by Dudarev et al. ${ }^{59}$ to correct the on-site Coulomb interaction between $\mathrm{Fe} 3 d$ orbitals. As in previous DFT studies of the $\mathrm{FeO} / \mathrm{Pt}(111)$ system $^{30,60,61}$ we used the projector augmented wave method ${ }^{62,63}$ and chose the parameters describing the on-site Coulomb interaction between Fe $3 d$ orbitals as $U_{\text {eff }}=U-J=3 \mathrm{eV}$. To model the $1 \mathrm{ML} \mathrm{FeO} / \mathrm{Pt}(111)$ surface we used the experimentally observed $(\sqrt{ } 91 \times \sqrt{ } 91) \mathrm{R} 5.2^{\circ}$ unit cell consisting of one layer of Fe atoms and one layer of $\mathrm{O}$ atoms supported on a three-layer $\mathrm{Pt}(111)$ slab. The FeO film, all adsorbates and the top Pt layer were fully relaxed, while the bottom two layers were fixed at bulk positions using the experimental value for the Pt-Pt spacing in the (111) plane of $2.77 \AA$ (that is, an average $\mathrm{Fe}-\mathrm{Fe}$ spacing of $3.09 \AA$ ). The Brillouin zone was sampled with the gamma point only. Exchange and correlation were described by the GGA-PW91 exchange-correlation functional ${ }^{64}$; a kinetic energy cutoff of $400 \mathrm{eV}$ was used. The initial guess for the magnetic structure is based on a row-wise anti-ferromagnetic structure, with a magnetic defect, due to the odd number of Fe atoms at the TOP domain ${ }^{30}$.

\section{References}

1. Verdaguer, A., Sacha, G. M., Bluhm, H. \& Salmeron, M. Molecular structure of water at interfaces: wetting at the nanometer scale. Chem. Rev. 106, 1478-1510 (2006).

2. Thiel, P. A. \& Madey, T. E. The interaction of water with solid surfaces: Fundamental aspects. Surf. Sci. Rep. 7, 211-385 (1987).

3. Henderson, M. A. The interaction of water with solid surfaces: fundamental aspects revisited. Surf. Sci. Rep. 46, 1-308 (2002)

4. Hodgson, A. \& Haq, S. Water adsorption and the wetting of metal surfaces. Surf. Sci. Rep. 64, 381-451 (2009).

5. Carrasco, J., Hodgson, A. \& Michaelides, A. A molecular perspective of water at metal interfaces. Nat. Mater. 11, 667-674 (2012).

6. Carrasco, J. et al. A one-dimensional ice structure built from pentagons. Nat. Mater. 8, 427-431 (2009).

7. Nie, S., Feibelman, P. J., Bartelt, N. C. \& Thürmer, K. Pentagons and heptagons in the first water layer on Pt(111). Phys. Rev. Lett. 105, 026102 (2010).

8. Cerdá, J. et al. Novel water overlayer growth on $\mathrm{Pd}(111)$ characterized with scanning tunneling microscopy and density functional theory. Phys. Rev. Lett. 93, 116101 (2004).

9. He, Y. et al. Nucleation and growth of $1 \mathrm{D}$ water clusters on rutile $\mathrm{TiO}_{2}(011)$ $(2 \times 1)$. J. Phys. Chem. C 113, 10329-10332 (2009).

10. Brown, G. E. et al. Metal oxide surfaces and their interactions with aqueous solutions and microbial organisms. Chem. Rev. 99, 77-174 (1999).

11. Salmeron, M. et al. Water growth on metals and oxides: binding, dissociation and role of hydroxyl groups. Faraday Discuss. 141, 221-229 (2009).

12. Joseph, Y., Ranke, W. \& Weiss, W. Water on $\mathrm{FeO}(111)$ and $\mathrm{Fe}_{3} \mathrm{O}_{4}(111)$ : adsorption behavior on different surface terminations. J. Phys. Chem. B 104, 3224-3236 (2000).

13. $\mathrm{Xu}, \mathrm{L}$. et al. Oxygen vacancy-induced novel low-temperature water splitting reactions on $\mathrm{FeO}(111)$ monolayer-thick film. J. Phys. Chem. C 116, 22921-22929 (2012).

14. Meyer, B. et al. Partial dissociation of water leads to stable superstructures on the surface of zinc oxide. Angew. Chem. Int. Ed. 43, 6642-6645 (2004).

15. Parkinson, G. S., Novotný, Z., Jacobson, P., Schmid, M. \& Diebold, U. Room temperature water splitting at the surface of magnetite. J. Am. Chem. Soc. 133, 12650-12655 (2011).

16. Rim, K. T. et al. Scanning tunneling microscopy and theoretical study of water adsorption on $\mathrm{Fe}_{3} \mathrm{O}_{4}$ : implications for catalysis. J. Am. Chem. Soc. 134, 18979-18985 (2012).

17. Matthiesen, J. et al. Formation and diffusion of water dimers on rutile $\mathrm{TiO}_{2}$ (110). Phys. Rev. Lett. 102, 226101 (2009).

18. Ma, H. et al. Nano-ice on boron nitride nanomesh: accessing proton disorder ChemPhysChem 11, 399-403 (2010).

19. Picolin, A. et al. Desorption of $\mathrm{H}_{2} \mathrm{O}$ from flat and stepped $\mathrm{Pt}(111)$. J. Phys. Chem. C 113, 691-697 (2009).

20. Vurens, G. H., Salmeron, M. \& Somorjai, G. A. Structure, composition and chemisorption studies of thin ordered iron-oxide films on platinum(111). Surf. Sci. 201, 129-144 (1988).

21. Galloway, H. C., Benitez, J. J. \& Salmeron, M. The structure of monolayer films of FeO on Pt(111). Surf. Sci. 298, 127-133 (1993).

22. Rienks, E. D. L., Nilius, N., Rust, H.-P. \& Freund, H.-J. Surface potential of a polar oxide film: FeO on Pt(111). Phys. Rev. B 71, 241404 (2005).

23. Nilius, N., Rienks, E. D. L., Rust, H. P. \& Freund, H.-J. Self-organization of gold atoms on a polar FeO(111) surface. Phys. Rev. Lett. 95, 066101 (2005).

24. Lin, X. \& Nilius, N. Self-assembly of MgPc molecules on polar FeO thin films. J. Phys. Chem. C 112, 15325-15328 (2008).

25. Daschbach, J. L., Dohnálek, Z., Liu, S.-R., Smith, R. S. \& Kay, B. D. Water adsorption, desorption, and clustering on $\mathrm{FeO}(111)$. J. Phys. Chem. B 109, 10362-10370 (2005).

26. Leist, U., Ranke, W. \& Al-Shamery, K. Water adsorption and growth of ice on epitaxial $\mathrm{Fe}_{3} \mathrm{O}_{4}(111), \mathrm{FeO}(111)$ and $\mathrm{Fe}_{2} \mathrm{O}_{3}$ (biphase). Phys. Chem. Chem. Phys. 5, 2435-2441 (2003)

27. Huang, W. X. \& Ranke, W. Autocatalytic partial reduction of $\mathrm{FeO}(111)$ and $\mathrm{Fe}_{3} \mathrm{O}_{4}$ (111) films by atomic hydrogen. Surf. Sci. 600, 793-802 (2006).

28. Knudsen, J. et al. Reduction of $\mathrm{FeO} / \mathrm{Pt}(111)$ thin films by exposure to atomic hydrogen. Surf. Sci. 604, 11-20 (2010).

29. Merte, L. R. et al. Water-mediated proton hopping on an iron oxide surface. Science 336, 889-893 (2012).

30. Merte, L. R. et al. Tip-dependent scanning tunneling microscopy imaging of ultrathin FeO films on Pt(111). J. Phys. Chem. C 115, 2089-2099 (2011).

31. Merte, L. R. et al. Correlating STM contrast and atomic-scale structure by chemical modification: vacancy dislocation loops on FeO/Pt(111). Surf. Sci. 603, L15-L18 (2009)

32. Giordano, L. et al. Charging of Metal Adatoms on Ultrathin Oxide Films: Au and Pd on FeO/Pt(111). Phys. Rev. Lett. 101, 026102 (2008).

33. Giovambattista, N., Debenedetti, P. G. \& Rossky, P. J. Effect of surface polarity on water contact angle and interfacial hydration structure. J. Phys. Chem. B 111, 9581-9587 (2007) 
34. Ong, S., Zhao, X. \& Eisenthal, K. B. Polarization of water molecules at a charged interface: second harmonic studies of the silica/water interface. Chem. Phys. Lett. 191, 327-335 (1992).

35. Michaelides, A. \& Morgenstern, K. Ice nanoclusters at hydrophobic metal surfaces. Nat. Mater. 6, 597-601 (2007).

36. Nauta, K. \& Miller, R. E. Formation of cyclic water hexamer in liquid helium: the smallest piece of ice. Science 287, 293-295 (2000).

37. Petrenko, V. F. \& Whitworth, R. W. Physics of Ice (Oxford University Press, 2002).

38. Zhao, H.-X. et al. Transition from one-dimensional water to ferroelectric ice within a supramolecular architecture. Proc. Natl Acad. Sci. USA 108, 3481-3486 (2011).

39. Buch, V., Groenzin, H., Li, I., Shultz, M. J. \& Tosatti, E. Proton order in the ice crystal surface. Proc. Natl Acad. Sci. USA 105, 5969-5974 (2008).

40. Li, X.-Z., Walker, B. \& Michaelides, A. Quantum nature of the hydrogen bond. Proc. Natl. Acad. Sci. USA 108, 6369-6373 (2011).

41. Santra, B., Michaelides, A. \& Scheffler, M. On the accuracy of densityfunctional theory exchange-correlation functionals for $\mathrm{H}$ bonds in small water clusters: benchmarks approaching the complete basis set limit. J. Chem. Phys. 127, 184104 (2007).

42. Albrecht, L., Chowdhury, S. \& Boyd, R. J. Hydrogen bond cooperativity in water hexamers: atomic energy perspective of local stabilities. J. Phys. Chem. A 117, 10790-10799 (2013)

43. Znamenskiy, V. S. \& Green, M. E. Quantum calculations on hydrogen bonds in certain water clusters show cooperative effects. J. Chem. Theory Comput. 3, 103-114 (2007).

44. Gilli, P., Pretto, L., Bertolasi, V. \& Gilli, G. Predicting hydrogen-bond strengths from acid-base molecular properties. The $\mathrm{pK}_{\mathrm{a}}$ slide rule: toward the solution of a long-lasting problem. Acc. Chem. Res. 42, 33-44 (2009).

45. Giordano, L., Goniakowski, J. \& Suzanne, J. Partial dissociation of water molecules in the $(3 \times 2)$ water monolayer deposited on the $\mathrm{MgO}(100)$ surface. Phys. Rev. Lett. 81, 1271-1273 (1998).

46. Cabrera-Sanfelix, P., Fernández-Serra, M. V., Arnau, A. \& Sánchez-Portal, D. Substrate-induced cooperative effects in water adsorption from density functional calculations. Phys. Rev. B 82, 125432 (2010).

47. Clay, C., Haq, S. \& Hodgson, A. Hydrogen bonding in mixed $\mathrm{OH}+\mathrm{H}_{2} \mathrm{O}$ overlayers on Pt(111). Phys. Rev. Lett. 92, 046102 (2004).

48. Michaelides, A. \& Hu, P. Catalytic water formation on platinum: a firstprinciples study. J. Am. Chem. Soc. 123, 4235-4242 (2001).

49. Kimmel, G. A., Petrik, N. G., Dohnálek, Z. \& Kay, B. D. Crystalline ice growth on $\mathrm{Pt}(111)$ : observation of a hydrophobic water monolayer. Phys. Rev. Lett. 95, 166102 (2005)

50. Kimmel, G. A. et al. No confinement needed: observation of a metastable hydrophobic wetting two-layer ice on graphene. J. Am. Chem. Soc. 131, 12838-12844 (2009).

51. Hu, X. L. \& Michaelides, A. Water on the hydroxylated (001) surface of kaolinite: from monomer adsorption to a flat 2D wetting layer. Surf. Sci. 602, 960-974 (2008).

52. Feibelman, P. J. Viscosity of ultrathin water films confined between aluminol surfaces of kaolinite: $a b$ initio simulations. J. Phys. Chem. C 117, 6088-6095 (2013).

53. Haria, N. R., Grest, G. S. \& Lorenz, C. D. Viscosity of nanoconfined water between hydroxyl basal surfaces of kaolinite: classical simulation results. J. Phys. Chem. C 117, 6096-6104 (2013).

54. Weiss, W. \& Somorjai, G. A. Preparation and structure of 1-8 monolayer thick epitaxial iron oxide films grown on Pt(111). J. Vac. Sci. Technol. A 11, 2138-2144 (1993).

55. Lægsgaard, E., Besenbacher, F., Mortensen, K. \& Stensgaard, I. A fully automated, thimble-size scanning tunnelling microscope. J. Microsc. 152, 663-669 (1988).
56. Nečas, D. \& Klapetek, P. Gwyddion: an open-source software for SPM data analysis. Cent. Eur. J. Phys. 10, 181-188 (2012).

57. Kresse, G. \& Furthmüller, J. Efficient iterative schemes for ab initio total-energy calculations using a plane-wave basis set. Phys. Rev. B 54, 11169-11186 (1996).

58. Kresse, G. \& Furthmüller, J. Efficiency of $a b$-initio total energy calculations for metals and semiconductors using a plane-wave basis set. Comput. Mater. Sci. 6 , 15-50 (1996).

59. Dudarev, S. L., Botton, G. A., Savrasov, S. Y., Humphreys, C. J. \& Sutton, A. P. Electron-energy-loss spectra and the structural stability of nickel oxide: An LSDA + U study. Phys. Rev. B 57, 1505-1509 (1998).

60. Giordano, L. et al. Interplay between structural, magnetic, and electronic properties in a FeO/Pt(111) ultrathin film. Phys. Rev. B 76, 075416 (2007).

61. Zhang, W., Li, Z., Luo, Y. \& Yang, J. First principles study on the geometric and electronic structures of the FeO/Pt (111) surface. J. Phys. Chem. C 113, 8302-8305 (2009).

62. Blöchl, P. E. Projector augmented-wave method. Phys. Rev. B 50, 17953-17979 (1994).

63. Kresse, G. \& Joubert, D. From ultrasoft pseudopotentials to the projector augmented-wave method. Phys. Rev. B 59, 1758-1775 (1999).

64. Perdew, J. P. \& Wang, Y. Accurate and simple analytic representation of the electron-gas correlation energy. Phys. Rev. B 45, 13244-13249 (1992).

\section{Acknowledgements}

Work at Aarhus University was supported by the Danish Research Agency, the Strategic Research Council, the Villum Foundation, the Carlsberg Foundation, the Lundbeck Foundation, the European Research Council through an Advanced ERC grant (FB) and Haldor Topsøe A/S. Work at UW-Madison was supported by DOE-BES, the Division of Chemical Sciences (grant DE-FG02-05ER15731) and by the Air Force Office of Scientific Research under a Basic Research Initiative grant (AFOSR FA9550-12-1-0481). C.A.F. thanks the NSF for partial support, through a graduate fellowship. The computational work was performed in part using supercomputing resources from the following institutions: the EMSL, a National scientific user facility at the Pacific Northwest National Laboratory (PNNL); the Center for Nanoscale Materials (CNM) at the Argonne National Laboratory (ANL); and the National Energy Research Scientific Computing Center (NERSC). The EMSL is sponsored by the the Department of Energy's Office of Biological and Environmental Research located at PNNL. the CNM and the NERSC are supported by the US Department of Energy, Office of Science, under Contracts DE-AC0206CH11357, and DE-AC02-05CH11231, respectively.

\section{Author contributions}

F.B. and M.M. supervised the project. L.R.M. and R.B. designed the experiments. L.R.M., R.B., F.R., H.Z., J.K. and E.L. conducted the experiments. G.P. and C.A.F. performed the DFT calculations. L.R.M. evaluated the data and prepared the manuscript with discussions and input from all coauthors.

\section{Additional information}

Supplementary Information accompanies this paper at http://www.nature.com/ naturecommunications

Competing financial interests: The authors declare no competing financial interest.

Reprints and permission information is available online at http://npg.nature.com/ reprintsandpermissions/

How to cite this article: Merte, L. R. et al. Water clustering on nanostructured iron oxide films. Nat. Commun. 5:4193 doi: 10.1038/ncomms5193 (2014). 